\title{
Effect of Psychological Pressure (mobbing) on Business life and Employee
}

\section{Mustafa YILDIRIM}

Institute of Management Business and Law, Russia

(C) The Author(s) 2018

\section{ABSTRACT}

Mobbing as defined as psychological pressure or coercion directed towards employees in organizations, poses serious negativities in terms of businesses and employees. Threats arises from the activities in the workplace are not only limited to work accidents and illnesses. Psychological pressure and harassment existing among the employees who share the same place in the same environment gradually turn into pain and suffering on the victim, causing problems that can't be solved.

Mobbing which is subject to legal regulations in many countries today is a type of violence that must be fought against. The aim of this study is to try to determine the effects of mobbing that exists in work life on occupational life and the employee and to make necessary recommendations.

(C)2018. All rights reserved.

\section{ARTICLE HISTORY}

Received: $11 / 03 / 2018$

Accepted: 19/06/2018

Published online: 05/10/2018

\section{KEYWORDS}

Psychological pressure, mobbing, occupational life, business, employees 


\section{Introduction}

For human beings existing in the production process throughout their business life, it becomes inevitable that the health and safety of the person becomes imperiled under the threats of the workplace, the struggle with increasing tools, equipment and machines, and the environment in which the workplace emerges as a result of this struggle. Every year, thousands of people around the world, depending on the work they do, are spend the rest of their lives in validity and disability or lose their lives as a result of work accident or occupational illness (Tinaz, 2006).

The involvement of communication and media tools in our whole lives has affected the relationship between people in different ways; selfishness and individualism have come to the forefront. People try to resolve all their sorrows and joys on their own, instead of sharing the sadness and joy with each other. In global life, people have become the elements that are jealous of, upset and agonize each other while they need to be a source of love and joy for one another. The reflections of this change in the workplace put forward the concept of 'Mobbing'.

Mobbing defined as a behavior that can cause an individual to suffer physically and psychologically (Leymann, 2007), it is actually a phenomenon that has been constantly present throughout the business life, but is not clearly named. Recently, legal arrangements and struggles have been started on this issue internationally, and the significance of the mobbing issue has increased (Ünsal, 1996).

There is no end to the psychological harassment that occurs in different forms and tactics seen almost everywhere in the world. It is not a matter of gender, race, religion, name, or any place of the world to be a victim of this abuse, and that does not mean much.

The main thing that we need to put emphasis on is that, we need to be aware of the fact that these human resources is the most valuable asset for the workplace and organization, and that we have to act according to this consciousness and take precautions accordingly, since the knowledgeable, qualified and efficient human resources are limited in business life and everywhere in the world.

\section{The Effects of Psychological Pressure on Employees}

In today's information age, most of the businesses have come to the agreement that the most important element in order to achieve their goals and to 
gain competitiveness against their competitors is the employees in the business (Ergün, 2008).

Considering that the victims of mobbing are conscientious, honest and successful individuals, it is understood from the researches that the exclusion of these people due to psychological harassment will be a significant loss in terms of both the employers and society. The consequences of psychological harassment, which has become one of the main problems modern life brings, and it's spheres of influence have just begun to be understood;

Attitudes and behaviors of people regarding this issue started to change, and their information about this issue has begun to increase.

Problems begin as a result of the rude, disrespectful and damaging behaviors of the individual or group towards abusive individuals, and these problems continue to multiply over time. In the next stage, the person who is experiencing the abuse might face with accusations such as problematic, mentally ill or incompetent.

Generally it can progress to the point where one can leave the job by applying the systematic pressure against that person to lower and damage the one's social reputation.

H. Leyman identified the physical and emotional effects of psychological harassment on the individual as; insomnia, nervous breakdown, melancholy, impaired concentration, social isolation, self-contempt and humiliation, social dissonance, various psychological disorders, depression, hopelessness and despair, nervousness, anger and deep grief (Leyman, 2007).

Where the organization is weak in culture and communication, the individuals who are psychologically abused, the families of these individuals and their circles are affected negatively by this process.

The things that affect the victim most in the mobbing process are the frequency, the repetition and the duration of the psychological violence. As the psychological violence and the duration increases, the effect of this violence also increases. Everyone's endurance limit to psychological violence is different from each other. A situation that is tolerable for someone can cause great harm to others. Frequent and long-lasting psychological violence affects the psychological, physiological and social order of the victim in a negative way. These individuals experience various physiological, psychological and social problems, especially due to intense stress and anxiety. 
It is certain that the systematic psychological attack has adversely affected the person's mood. Tarhan pointed out that if the mobbing is continued for a long time, the psycho-somatic diseases will start and it can cause symptoms such as stomach, heart, skin and intestinal disorders besides the people exposed to mobbing make mistakes over and over again in the workplace and cause either near miss accidents or job accidents (Tarhan,2016).

Not only the health of the individuals exposed to psychological abuse but also the performance of their work is affected negatively. Problems such as job satisfaction, job performance and productivity decrease, decrease in motivation, increase in work-related error rates, decrease in work and institutional loyalty are also very common behaviors of the person who is the target of direct psychological harassment (Devenport, Swartz \& Elliot,2003).

Insecure environment within the organization creates negative pressure on other employees and the job-working atmosphere is affected. Employees' attention is distracted from the aims and objectives of the organization, and individuals witnessing such behaviors are able to direct themselves to unethical behaviors within the institution in order to guarantee their future and not to deal with such behaviors (Çukur,2003).

In times of unemployment and economic crises, while psychological harassment at work is increasingly violent, it is seen that the workers who are afraid of losing their jobs and struggle to make a living accustomed to these situations willingly or unwillingly and that they have a tendency to endure the pressure and intimidation encountered.

\section{The Effects of Psychological Pressure in the Workplace on Business Life}

In our world where it is easy to reach technology and difficult to reach trained, qualified and knowledgeable business people (Zap, Kronz \& Kulla, 1994), it can be better understood how important the loss of businesses is when it is thought that mobbing has been applied to qualified workers who have a high sense of belonging to their organization and who integrate with their work.

In addition to other financial losses, the loss of practical and experienced workers will be a huge loss for the employer too (Yücetürk, 2008). At the beginning of the negative effects of psychological pressure on workplaces comes the reluctant act and becoming distant of the victim towards the process and rule within the whole organization. Other employees who have witnessed psychological intimidation will also be affected by this situation and will also think that they would be exposed to such behavior as well. 
In consequence of mobbing, businesses will lose their trained employee at critical points of workplace and this will lead to an increase in the labor turnover, deterioration of unity and cohesion in the workplace, a consequent complexity of business caused by deterioration of the overall structure of the workplace, thereby weakening the business (Tinaz, 2006).

The direct cost of psychological harassment at workplace is the heavy burden that employees have to pay for with their own psychological and physical health, as well as the job loss and safety aspect of this situation which they have had to endure. The indirect cost of this phenomenon manifests itself in the form of low efficiency, disruption of production and product quality, loss of institutional prestige and customer dissatisfaction that employers and the society have to bear.

Furthermore, among the indirect costs that are as important as the economic costs, the loss of income resulting from absenteeism due to health expenditures, medical treatment and discomfort should also take into account as well.

When the cost of psychological harassment at workplace is evaluated, the following factors come to the forefront. The most significant effect of psychological pressure on work places is the change in attitude of the exposed person against all rules and procedures of the organization. Besides, the other workers who witness these repressions will be affected and unrest will start within the organization (Barlas, 1981).

The absenteeism of the victim and late arrivals to work will start to increase constantly, so that there will be a setback in the tasks in which victim is responsible, which will increase the work load of the other employees, and the uneasiness between the employees against both the victim and the organization will begin (Hoel, Einarsen \&Cooper).

Over time, the person who is experiencing the psychological abuse at work will tend to not work properly in the workplace, the labor turnover rate of that person will increase, person will start to look for new jobs due to the increasing uneasiness and pressure and his/her sense of belonging towards the organization will decrease. Due to the departure of trained and experienced individuals from the workforce, the cost of training will increase with the recruitment of new staff to the workplaces as a result of the loss of experienced personnel in the organization (Yücetürk,2005).Organizations will lose key employees, unrest will start in the workplace, trainings and adaptation of new employees will take time (Lorho, Hilp, 2001). 
In addition to the compensation that will be incurred if the persons leaving the work resorted to the legal ways and the companies are sued, the general expenses will bring big burdens on the organizations.

Employees' organizational loyalty will drop and their performances will decrease (Şehrinaz, 2005). Negative talks of the employees due to the negative conditions of the environment related to the work place, which are occur outside of work, will negatively affect the prestige of the company. The negativities at work will negatively affect organizational culture and climate, productivity will decrease, job quality will be low therefore workplace dissatisfaction will start to show itself.

The direct and indirect cost of psychological pressure is a very dramatic price that an individual has to pay with his physical and mental health, along with the economic troubles the employee and their relatives have had to endure. The cost of this phenomenon to the employer, the state and the society show itself as; the low efficiency that the employer, the society and the society have to bear, the deterioration of the production quality, the deterioration of the organization and the company's reputation, and the customer dissatisfaction.

Psychological harassment is costly to businesses, large enough to be expressed in million dollars. Psychologically disturbed workers will have less of an impact on productivity than those who work without problems. The loss of work force caused by illness and low efficiency will cause great loss both in workplaces and in the country's economy. The high cost of psychological harassment to work places; it is clear that this problem is a problem that needs to be solved urgently and is in the interest of all parties.

\section{Conclusion and Recommendations}

It is certain that businesses which have strong ties among employees, where respect, trust, cooperation, tolerance and assistance are common will be more successful and that competitiveness will increase compared to other competitors.Peaceful and secure business environments will bring peaceful people, families and therefore peaceful societies. The peace and happiness of society will open the way for future generations, and countries will be safer and prosperous.

There is no limit when taking precautions for occupational health and safety. Raising the quality of working life in a peaceful, healthy and safe environment emerges as the ethical responsibility that all managers must take against employees (Şimşek, 1999). 
Based on the information obtained from these results, we can explain the suggestions that can be made as follows. Psychological pressure should not be regarded as a simple conflict, but as a behavioral disorder that has permanent and detrimental effects later on. Democratic environments in which the participation of all employees are supported in the working environment should be ensured (Güngör, 2008). Employees should be informed about the causes and consequences of psychological repression and an effective complaints and a solution mechanism should be established (Bianed 2008).

It is necessary to provide an environment that encourages emotions such as business association, cooperation and sharing among employees. A strong ethical culture should be established among the organizations and psychological counseling should be provided to the employees when it is necessary. Psychological pressure should be accepted as an illegal and unethical behavior and should be regarded as a criminal offense which requires criminal responsibility; moreover legal infrastructure must be formed by making necessary legal regulations.

\section{Disclosure statement}

No potential conflict of interest was reported by the author.

\section{Contact Information}

E-mail: m.yildirim@gmail.com 


\section{References and notes:}

Amrendra .K. S, Nirbhay K. M. 2018.Ethical theory \& business. International Journal of Humanities and Social Development Research. Vol. 2(1), Baku, Azerbaijan.97-112

Barlas T. 'The Crisis Of Contemporary Society: Anatomy and Ankara Academy of Economics, Administrative and Commercial Sciences Publications.; 1981,p.184

BİANET. 'Employer Has To Prevent Psychological Harassment', Tolga Korkut, 21 July 2008 .

Çukur, C. Psychological Harassment In The Workplace In Turkish Law And Comparative Law.2009.

D. Zapf \& C. Knorz \& M. Kulla. 'On The Relationship Between Mobbing Factors and Job Content, Social Work Environment and Health Outcomes,Europan Journal of Work and Organizational Psycholgy,1994,pp..383.

Davenport, N . Swartz, R.D. ve Elliott, G.P. 2003. Mobbing: Emotional Harassment at Workplaces.

Ergün, Ö. Derya, A Research on the Effect of Mobbing on Organizational Commitment, Dumlupinar University, Journal of Social Sciences, S:22,December, 2008

Güngör, M. Psychological Harassment in Working Life, Derin Publishing, İstanbul, 2008, $\mathrm{s}: 1$.

H. Hoel, S. Einarsen, ve C. L. Cooper,' Organisational Effects Of Bullying', Bullying and Emotional Abuse in the Workplace, International Perspectives in Research and Practice http://.bullyonline.org/workbully/costs.htm=employer.

Leyman H.' 'Mobbing and Psyhological Terror at Workplaces' Violence and Victims, Springer Publishing Company, Volume 5, No:2,p..122

Leyman, H. 'Research and the Tern Mobbing', The Mobbing Encyclopedia,

Lorho, Frank ve Hilp,Ulrich (2001) European Parliament Directorate-General For Research Working Paper Bullying At Work

Polat, Ş. The Concept of Job-Knit Loyalty and Job Satisfaction and Job Separation Relation and a Research on Nurses.', Istanbul University Social Sciences Institute, Doctorate thesis.,2005,

Royal College of Nursing(RCN) Working Well Initiative, Bullying and Harrasment at Work: London,2002,p.3

S. Einarsen, H. Hoel, D. Zapf, ve C .L . Cooper (Eds),s.145/161,London \& Newyork: Taylar \& Francis,2003,p. 147

Şimşek, B. 'Ethical Responsibilities of Managers to Employees...', Dokuz Eylül University Journal of Social Sciences Institute, C.1.S.3,1999,pp.69-86.

Tarhan N, http://www.memurlar.net/haber/531032/

Tinaz, P. (2006), Psychological Harassment at Work (Mobbing),Beta Publishing, İstanbul, p. 157

Tınaz, P. (2006); Psychological Harassment at Work (mobbing), Beta Publishing, İstanbul, p. 8

Unsal A, An Extended Typology Of Violence.'Cogito, s,6-,Kış-Bahar,1996,p.29.

Yücetürk, E., The Invisible Face of Organizations in the Information Age.: Mobbing.p.6

Yücetürk,E.f.' Unstoppable Intimidation Practices In Organizations Are Dreams Real'.p.5 